\title{
Scaffolding a collaborative process through concept mapping: a case study on faculty development
}

\author{
Joana G. Aguiar \\ Programa de Pós-Graduação Interunidades em Ensino de Ciências, \\ Universidade de São Paulo, São Paulo, Brazil \\ Alfred E. Thumser, Sarah G. Bailey, Sarah L. Trinder, \\ Ian Bailey and Danielle L. Evans \\ Department of Biochemistry, University of Surrey, Guildford, UK, and \\ Ian M. Kinchin \\ Department of Higher Education, University of Surrey, Guildford, UK
}

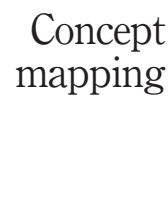

Received 19 October 2018

Revised 5 February 2019 Accepted 6 April 2019

\begin{abstract}
Purpose - Concept maps have been described as a valuable tool for exploring curriculum knowledge. However, less attention has been given to the use of them to visualise contested and tacit knowledge, i.e. the values and perceptions of teachers that underpin their practice. This paper aims to explore the use of concept mapping to uncover academics' views and help them articulate their perspectives within the framework provided by the concepts of pedagogic frailty and resilience in a collaborative environment.
\end{abstract}

Design/methodology/approach - Participants were a group of five colleagues within a Biochemical Science Department, working on the development of a new undergraduate curriculum. A qualitative singlecase study was conducted to get some insights on how concept mapping might scaffold each step of the collaborative process. They answered the online questionnaire; their answers were "translated" into an initial expert-constructed concept map, which was offered as a starting point to articulate their views during a group session, resulting in a consensus map.

Findings - Engaging with the questionnaire was useful for providing the participants with an example of an "excellent" map, sensitising them to the core concepts and the possible links between them, without imposing a high level of cognitive load. This fostered dialogue of complex ideas, introducing the potential benefits of consensus maps in team-based projects.

Originality/value - An online questionnaire may facilitate the application of the pedagogic frailty model for academic development by scaling up the mapping process. The map-mediated facilitation of dialogue

(C) Joana G. Aguiar, Alfred E. Thumser, Sarah G. Bailey, Sarah L. Trinder, Ian Bailey, Danielle L. Evans and Ian M. Kinchin. Published in PSU Research Review. Published by Emerald Publishing Limited. This article is published under the Creative Commons Attribution (CC BY 4.0) licence. Anyone may reproduce, distribute, translate and create derivative works of this article (for both commercial and non-commercial purposes), subject to full attribution to the original publication and authors. The full terms of this licence may be seen at http://creativecommons.org/licences/by/4.0/ legalcode

JGA thanks the Coordination for the Improvement of Higher Education Personnel (CAPES) for the financial support, number 88881.135605/2016-01. JGA and IMK are particularly grateful for the assistance given by Prof Dr Paulo Correia from the University of São Paulo.

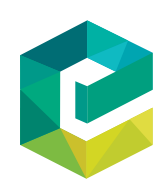

PSU Research Review Vol. 3 No. 2, 2019 
PRR

3,2

within teams of academics may facilitate faculty development by making explicit the underpinning values held by team members.

Keywords Collaboration, Concept mapping, Curriculum development, Faculty development, Questionnaire

Paper type Case study

\section{6}

\section{Introduction}

Concept mapping (Novak, 2010) has been used in numerous educational settings and is becoming a common feature in the higher education literature (Kinchin, 2014). Most of the studies that have been published to date have tended to concentrate on mapping curriculum knowledge (i.e. agreed knowledge). However, less attention has been given to the use of concept mapping to visualise contested knowledge which may have been regarded as tacit knowledge: the values and perceptions of teachers that underpins their practice (Lygo-Baker et al., 2008; McNaughton et al., 2016; van den Bogaart et al., 2017; McMillan and Gordon, 2017).

This study was undertaken with a group of five academic colleagues working within the same Biochemical Sciences Department who appeared to have a shared philosophy of teaching and were working on the development of a new undergraduate curriculum. The group was very positive about their teaching role, and their dialogue revealed explicit trust and respect for each other and were keen to develop their pedagogic scholarship (Rowland and Myatt, 2014). In a single-case study, we explore the use of concept mapping to not only uncover the academics' views about their teaching practice but also help them articulate their perspectives within the framework provided by the concepts of pedagogic frailty and resilience in a collaborative environment (Kinchin, 2017; Kinchin and Winstone, 2017). We expected the discussion and development of concept maps to facilitate a greater level of pedagogic resilience in the face of a wider environment that is considered by the participants to be resistant to radical change within the teaching sphere.

\section{Background}

There are many approaches to collaboration and cooperation in the existing literature (O’Donnell and Dansereau, 1992; De Lisi and Goldbeck, 1999; Dillenbourg et al., 1995; Fischer and Mandl, 2003; Kobbe et al., 2007). One of them, proposed by Fischer et al. (2002), distinguishes four processes of collaborative knowledge construction: externalisation of knowledge, elicitation of knowledge, integration-oriented consensus building and conflictoriented consensus building. Some studies indicated that a cooperative outcome was enhanced through the use of content-specific visualisation tools, such as concept maps (Roth and Roychoudhury, 1993; van Boxtel et al., 1997; Correia et al., 2014). Furthermore, concept maps has also been described as a valuable tool for collaborative academic faculty development (Kinchin et al., 2016; Kinchin et al., 2017).

Developed by Novak and colleagues in the 1970s (Novak, 2010), concept maps are graphical organisers useful for making explicit the relationship between concepts through propositions - that is, the relationships between pairs of concepts by a linking line and phrase (see an example in Figure 4). Concept mapping has been used to visualise and represent knowledge (Hay et al., 2008); foster deep or meaningful learning (Blunt and Karpicke, 2014); as an assessment tool (Ritchhart et al., 2009) and collaboration tool (Torres and Marriott, 2010). In this paper, we explored concept mapping to scaffold each step of the collaboration process. 
We step in the collaborative construction of knowledge is to include individual prior knowledge into the situation, i.e. externalise knowledge structures. According to Brown et al. (1989, p. 33), the exchange of different individual concepts is a good starting point for the negotiation of common meaning in discourse.

Concept maps can be used as an externalisation tool by offering a task that invites the individuals to provide evidence bearing on his or her knowledge structure in a domain (Shavelson et al., 2005; Kinchin, 2016). However, untrained users are more susceptible to cognitive overload during the map elaboration task (Aguiar and Correia, 2017). According to Cognitive Load Theory (Sweller et al., 2011) a task can be a source of two cognitive loads: the intrinsic load (i.e. load imposed to the learners' working memory, which is related to the content complexity) and the extraneous load (i.e. the unproductive load imposed to a learner's working memory, which does not contribute to learning). If both loads exceed the limits of working memory capacity, no resources are left to foster generative processes, namely, schema construction and manipulation or learning (van Merriënboer and Ayres, 2005; van Mierlo et al., 2012). The consequence would be a low-quality concept map, poor in structure and content, which does not represent the mapper's mental structure of knowledge.

Some research regarding this issue can be found in the literature. For example, Stull and Mayer (2007) showed that constructing graphic organisers with little training imposes a higher extraneous load, impairing learning. Hilbert and Renkl (2008) carried out a study to characterise good and poor concept mappers after developing an effective training. According to them, unsuccessful mappers rarely labelled the links that connect the concept nodes. On the other hand, effective mappers invested great effort into planning their mapping process to produce a coherent concept map. Conradty and Bogner (2010) studied the implementation of concept mapping for novices, showing that most errors found in mappers' propositions were content dependent, explaining this low-quality concept map feature due to a high intrinsic load.

To cope with these difficulties, we need to manage the intrinsic load and decrease the extraneous load as much as possible (Mayer and Moreno, 2009). In this paper, content complexity was reduced through an online questionnaire that split the content into parts of information. The extraneous load was decreased by providing a concept map produced by an expert on the technique, considering the criteria for an excellent content accuracy and graphical structure (Cañas et al., 2015; Correia and Aguiar, 2014).

\section{Elicitation of knowledge and consensus building}

The second step of collaborative knowledge construction is the elicitation process. This requires the participants to make statements or directives, request or provide explanations, give suggestions, agree or disagree with partners or groups to express or clarify knowledge during the task (Teasley, 1997). It is worth mentioning that concept mapping has been used successfully in the elicitation of implicit and tacit knowledge (Hoffman and Lintern, 2006).

The last step of collaborative construction of knowledge is the consensus building. To achieve a common solution for a given task, the participants in a group need to negotiate concepts and meanings (Weinberger et al., 2007). This consensus building is essential to achieve a high quality of cooperative outcome and can occur in different ways. The conflictoriented consensus building occurs when the participants make use of different interpretations (i.e. cognitive conflicts) to stimulate their understanding of the topic (Deutsch, 2003). On the other hand, integration-oriented consensus building occurs when the 
PRR

3,2

participants combine the variety of individual perspectives (i.e. integration) into a common interpretation (Hatano and Inagaki, 1991).

\section{Methodology}

We adopted a qualitative research approach by a case study as strategy of inquiry in this research. According to Creswell (2013):

[...] a qualitative study is defined as an inquiry process of understanding a social or human problem, based on building a complex, holistic picture, formed with words, reporting detailed views of informants, and conducted in a natural setting.

In this paradigm, it is sought to establish the meaning of a phenomenon from the views of participants, which means identifying a culture-sharing group and studying how it develops shared patterns of behaviour.

In this paper, the participants were a group of five academic colleagues working within the same Biochemical Sciences Department working on the development of a new undergraduate curriculum. The group shares of some teaching views; however, most of their perspectives are implicit and idiosyncratic. To better understand how concept mapping could be useful for scaffolding collaboration process, in this context, a research procedure as outlined in Figure 1 was conducted.

First, the participants were asked to answer the online questionnaire about the researchteaching nexus[1] with no constraints of time. They took an average of $19.3 \mathrm{~min}$ (standard deviation of $8.4 \mathrm{~min}$ ) to accomplish the task. Considering their answers to the questionnaire, the researcher (a map-expert) took approximately 20 min to produce individuals' concept map using Microsoft PowerPoint ${ }^{\circledR}$. These maps were printed on a A4 sheet and presented to the participants at the beginning of the group session.

The group session started with the research purposes and objectives. The participants analysed and discussed the separate concept maps and then developed a paper and pencil collaborative/consensus concept map. They had approximately $1 \mathrm{~h}$ to accomplish this task. Finally, the digital map (drawn using Microsoft PowerPoint ${ }^{(\mathbb{R}}$ ) was sent to the participants by e-mail with an evaluation form that invited them to provide feedback about the process, which will help us to improve the online questionnaire design for a future application.

\section{Online questionnaire design and individual concept map}

The questionnaire was designed in six parts (A-F). Each part had the purpose of identifying participants' conceptions and beliefs about one specific aspect of the of research-teaching nexus. The purpose, question type and answer format are provided in Table I. The Qualtrics survey platform was used to host the questionnaire, which it was controlled by password[2].

The participants' answers were downloaded and analysed to consider their content. Each part of the questionnaire provided information that was "translated" into concepts and propositions needed to draw the individual concept maps. To illustrated this protocol, we show a partial view of one participant's answers to the questionnaire Parts B (Figure 2) and $\mathrm{C}$ and D (Figure 3) and their correspondence to the concept map (Figure 4).

Good concept maps must fulfil some predefined criteria related to both graphical structure and content accuracy, such as organising concepts in a hierarchical way and constructing correct and relevant propositions (Cañas and Novak, 2006). In this paper, we followed these criteria to ensure construction of an "excellent" concept map, which is not only concise but also captures the complexity of the involved content (Cañas et al., 2015; Correia and Aguiar, 2014). 
Concept

mapping
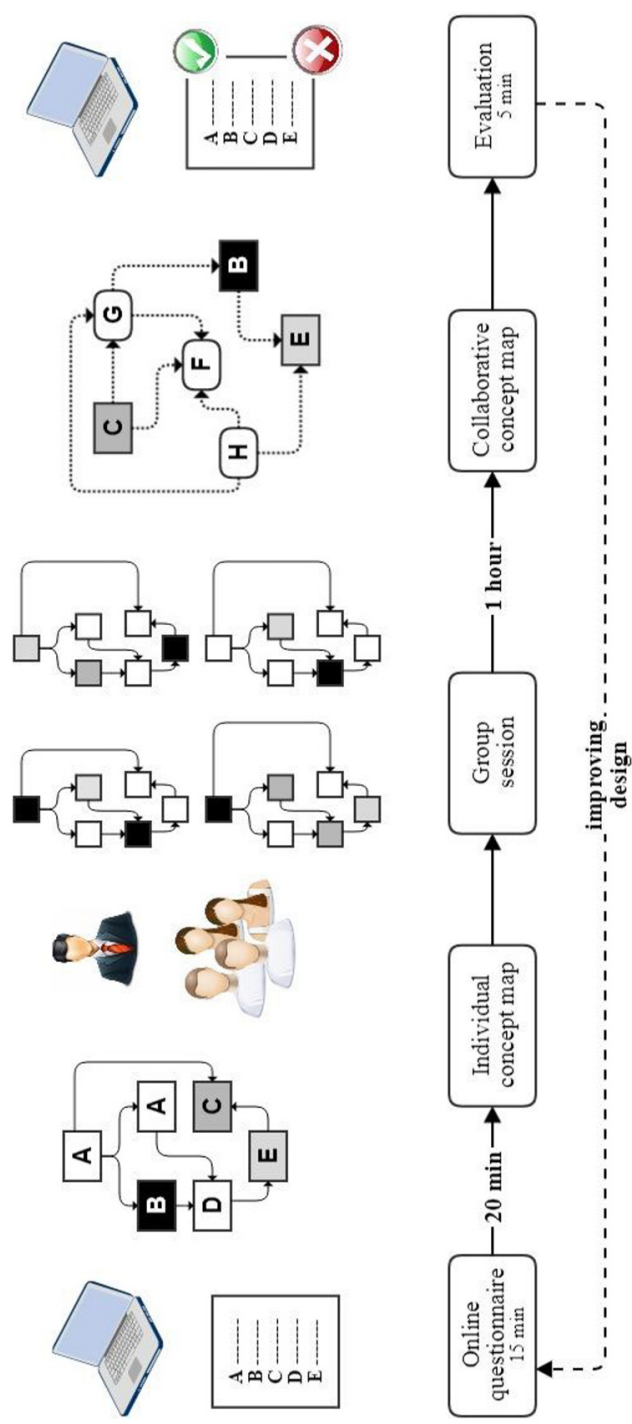

Figure 1. 


\begin{tabular}{llll} 
Part & Purpose & Question type & Answer format \\
\hline A & Level of importance & 14 scrambled & Rank order \\
and priority & research and & Rank in order of \\
considering teaching & teaching activities & importance and \\
and researching & & $\begin{array}{l}\text { priority when no } \\
\text { constraints of time is } \\
\text { activities }\end{array}$ & \\
& & imposed
\end{tabular}

Example

B Level of agreement considering some

30 statements to be judged general beliefs about research and teaching on higher education

C Personal beliefs when 6 questions that comparing research and teaching compare research rewards, recognition, and teaching motivation and status

\section{Multiple matrix} Jude using a 6-pointscale from $1=$

(a) Disciplinary research activities: manage approved grants and scholarships; engage on peer review paper or proposal.

(b) Teaching activities: lecture; grade students' assignments; prepare a lesson plan
(a) Research is overvalued by the academia;

strongly disagree to $6=$ strongly agree; plus the option N/A

\section{Multiple choices \\ Choose between} three options: more, less or equal

(b) The university has a systematic way to evaluate a good teacher;

(c) I usually encourage research in my classes

(a) For me, research generates [more | less | equal] motivation than teaching.

(b) The students valued the good researcher [more | less | equal] than a good teacher

D Examples of rewards, 6 questions that ask Short text entry recognition and for examples Maximum of 75 status on research and teaching characters allowed for each question

E Perception of how influential are some 'actors' for rewards, status and recognition within research and teaching

\section{2 questions} requesting the influence of university, colleagues, the

academic community, students, head of department and society

F General behaviour to a given scenario considering a tight deadline
2 questions that put some tension between research and teaching

\section{Slide bars}

Move the bars considering 0 (no influence) to 100 (very strong influence) for each actor

\section{Long text entry} Maximum of 1000 characters allowed for each question (a) In research, what does recognition look like?

(b) In teaching, the status can be a consequence of mainly two things:

Considering only the research activities, how influential is each of the below options in relation to rewards, recognition and status?

Imagine that you have a tight deadline to finish the following tasks: review your own paper that it is approved to be published; come up with an idea for a $\mathrm{PhD}$ grant proposal; plan the next lecture by selecting materials and the best learning approach; come up with an idea for an assessment task to evaluate your students

Table I.

Note: Each part of the questionnaire (A-F) had a purpose, a question type and an answer format. Some examples are provided 


\section{PART B}

\begin{tabular}{|c|c|c|c|c|c|c|c|c|}
\hline & & $\begin{array}{l}\text { Strongly } \\
\text { disagree }\end{array}$ & $\begin{array}{c}\text { Moderately } \\
\text { disagree }\end{array}$ & $\begin{array}{l}\text { Slightly } \\
\text { disagree }\end{array}$ & $\begin{array}{l}\text { Slightly } \\
\text { agree }\end{array}$ & $\begin{array}{l}\text { Moderately } \\
\text { agree }\end{array}$ & $\begin{array}{l}\text { Strongly } \\
\text { agree }\end{array}$ & N/A \\
\hline & $\begin{array}{l}\text { The students valued a } \\
\text { teacher that is also a } \\
\text { researcher }\end{array}$ & 6 & 0 & 0 & $\mathrm{c}$ & 0 & 0 & 0 \\
\hline & Teaching leads to recognition & 0 & 6 & 0 & 0 & 0 & 0 & 0 \\
\hline 1a & $\begin{array}{l}\text { Research is overvalued by } \\
\text { the academia }\end{array}$ & 0 & 0 & 0 & 0 & 0 & • & 0 \\
\hline 5 & $\begin{array}{l}\text { Research leads to } \\
\text { recognition }\end{array}$ & 0 & 0 & 0 & 0 & 0 & $\odot$ & 0 \\
\hline & $\begin{array}{l}\text { My teaching practice is } \\
\text { informed by research }\end{array}$ & 0 & 0 & 0 & • & 0 & 0 & 0 \\
\hline $3 a$ & $\begin{array}{l}\text { The university has a } \\
\text { systematic way to evaluate a } \\
\text { good teacher }\end{array}$ & 。 & 0 & 0 & c & 0 & 0 & 0 \\
\hline $1 \mathrm{~b}$ & $\begin{array}{l}\text { Teaching is undervalued by } \\
\text { the academia }\end{array}$ & 0 & 0 & 0 & 0 & 0 & • & 0 \\
\hline 6 & Teaching leads to high status & . & 0 & 0 & 0 & 0 & 0 & 0 \\
\hline & Teaching leads to rewards & 。 & 0 & 0 & 0 & c & 0 & 0 \\
\hline & $\begin{array}{l}\text { I usually encourage research } \\
\text { in my classes }\end{array}$ & 0 & 0 & 0 & 0 & 0 & 0 & • \\
\hline 2 & $\begin{array}{l}\text { Teaching means transmitting } \\
\text { new knowledge }\end{array}$ & 0 & 0 & 0 & 0 & 0 & $\odot$ & 0 \\
\hline $3 b$ & $\begin{array}{l}\text { The university has a } \\
\text { systematic way to evaluate a } \\
\text { good researcher }\end{array}$ & • & 0 & c & 0 & 0 & 0 & 0 \\
\hline & $\begin{array}{l}\text { Research means producing } \\
\text { new knowledge }\end{array}$ & 0 & 0 & • & 0 & 0 & 0 & 0 \\
\hline $7 a$ & Teaching leads to motivation & 0 & 0 & 0 & 0 & 0 & 。 & 0 \\
\hline & Research leads to rewards & 0 & 0 & 0 & 0 & • & 0 & 0 \\
\hline $7 b$ & $\begin{array}{l}\text { Motivation is needed for } \\
\text { researching }\end{array}$ & 0 & 0 & 0 & $\mathrm{c}$ & 0 & • & 0 \\
\hline & $\begin{array}{l}\text { Research helps on my } \\
\text { teaching practice }\end{array}$ & 0 & 0 & 0 & • & 0 & 0 & 0 \\
\hline 4 & $\begin{array}{l}\text { Teaching and research } \\
\text { should be more } \\
\text { interconnected }\end{array}$ & 0 & 0 & 0 & 0 & 0 & ह & 0 \\
\hline
\end{tabular}

Note: The statements (1-7b) were used to elaborate his individual concept map shown in Figure 4

To start drawing the concept map, we chose some key concepts to represent the research-teaching nexus (Kinchin et al., 2016): university, academia, students, research, teaching, rewards, recognition, status and motivation. We organised these concepts in a top-down hierarchy. For example, academia encompasses the completely academic community, including universities, at the top of the map. The examples regarding rewards and recognition should be on the bottom of the map as they are very specific and individualised.

As soon as the key concepts were hierarchically organised, we connected pairs of concepts through a directional arrow (to offer a reading flow) and a linking phrase with a proper verb. In other words, we established concise and clear propositions by using the statements judged as "strongly agree" or "strongly disagree" in Part B of the questionnaire (Figure 2). For example, the showcased individual academic strongly agreed that the academia overvalues research (1a, Figure 2) and undervalues teaching (1b, Figure 2). Both statements were transformed into propositions $1 \mathrm{a}$ and $1 \mathrm{~b}$ in Figure 4 . He also strongly disagreed that university has a systematic way to evaluate a good researcher (3a, Figure 2) and a good teacher (3b, Figure 2). In this case, the linking phrase received a negative connotation ("does not have") and it was shared to construct both propositions (see 3a and 


\section{PRR}

3,2

92

Figure 3.

One academic's responses to PARTC and PART D questionnaire

\author{
PART C \\ Please, choose the word in the list corresponding to the most appropriate \\ answer to each question that best fits your personal beliefs. \\ For me, research generates ( \\ recognition than teaching \\ c more 5 \\ Cless \\ Cequal \\ For me, research generates ( \\ motivation than teaching \\ O more \\ Cequal \\ • less 7 a
}

\section{PART D}

Please, write one or two words inside each box corresponding to the most appropriate answer to the question. Do not spend too much time on the task, if you cannot remember anything, just leave it blank.

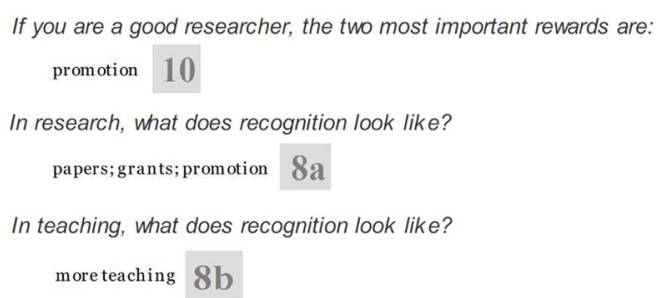

Note: The short answers (7a-10) were used to elaborate his individual concept map shown in Figure 4

$3 \mathrm{~b}$ in Figure 4). The same pattern can be seen for Statement 6 in the questionnaire; as he strongly disagreed that teaching leads to high status and rewards at the same time, the proposition was constructed with the negative "does not lead" and shared as a linking phrase for both propositions (see 6 in Figure 4).

Statement 2 in the questionnaire required adding "knowledge" as a new concept in the map, and Statement 4 required a double-headed arrow to represent a two-way relationship between "research" and "teaching" (see 2 and 4 in Figure 4). It is important to note that slight agreements or disagreements were disregarded when constructed the concept map, first, because we aimed to produce a consensus map with the academics' strongest views highlighting the difference between them and, second, because the use of "might", "can be", "perhaps", "sometimes" decreases the level of content accuracy and the map's explanatory feature. Finally, adding too many propositions would hamper the map's visual layout and readability (Derbentseva and Kwantes, 2014), which might be a source of disorientation and extraneous load (Amadieu et al., 2009) which reduce interpretation by the participants.

Statement number 5, for example, can be confirmed using two sources of information in the questionnaire. The academic strongly agreed that research leads to recognition (Part B, 


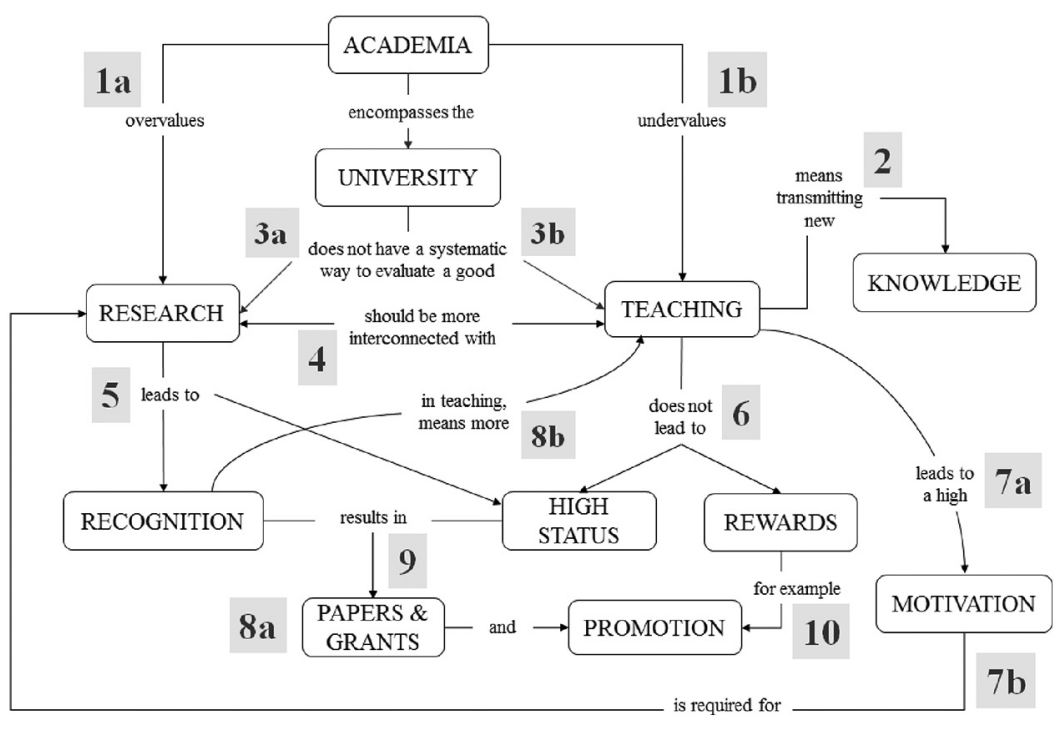

Note: Numbers refer to the numbering of questions in Figures 2 and 3
Concept mapping

93

Figure 2) which is higher than in teaching (Part C, Figure 3). The same pattern can be seen for Statement $7 \mathrm{a}$ in the questionnaire. In Part $\mathrm{B}$, he strongly agreed that teaching leads to motivation and in Part $\mathrm{C}$ he said that motivation is higher for teaching than research. Both answers produced the proposition 7a in the concept map (Figure 4). As he strongly agrees that motivation is needed for research, we created a new proposition 7b in the map (Figure 4).

Part D of the questionnaire (Figure 3) provided some examples to progressively detail how the academic understood the rewards, recognition and status within higher education. For example, in research, recognition looks like a grant, papers and promotion, but in teaching, it means more teaching ( $8 \mathrm{a}$ and $8 \mathrm{~b}$ in Figure 4). For him, one of the main consequence of high status in research is the papers and grants, but not promotion. Then, we decide to separate two concepts "paper and grants" and "promotion" so we can use the first one to establish the proposition number 9 in the map (Figure 4). Finally, as one of the institutional rewards is promotion, we used this concept to create the proposition number 10 in the concept map (Figure 4).

Parts $\mathrm{A}, \mathrm{E}$ and $\mathrm{F}$ of the questionnaire helped us to understand how the academics connect research and teaching and to identify any inconsistencies on their discourses. For instance, if in Part A, he/she affirmed that his/her teaching practice is informed by research, but in Part F, it is written that he/she cannot connect research and teaching in his/her academic life, we can identify an inconsistency that needs to be clarified. In this case, we can create a proposition with a question mark (e.g. Teaching - is informed by (?) $\rightarrow$ Research) and ask him/her to clarify and explain these propositions during the group session.

\section{Collaborative activity and evaluation}

Two researchers monitored the group discussion. At the beginning of the session, the researchers initiated some discussion about the research-teaching nexus and invited the 
PRR

3,2

94

group to review their individual maps and then (as a group) produce a consensus map that represents their view as a team. It is important to note that even though the academics were briefly introduced to the concept mapping technique, it was the first time they had produced one as a group. They were instructed to use any and as many concepts that they might consider important to express their views. They drew the map on a blank A3 sheet of paper using yellow self-stick notes and they took approximately 60 min to accomplish the task.

The digital concept map was sent to the academics by e-mail followed by some questions that invited them to evaluate the previous activities. Using a five-point Likert scale, this evaluation form[3] aimed to measure:

- Mental demand: from 1 (very low) to 5 (very high).

- Clarity of the questions: from 1 (very unclear) to 5 (very clear).

- Level of interest: from 1 (boring) to 5 (interesting).

- Level of challenge: from 1 (no challenging) to 5 (very challenging).

- Concept map accuracy: from 1 (inaccurate) to 5 (accurate).

- Concept map helpfulness as a visualisation tool: from 1 (unhelpful) to 5 (very helpful).

It also asked the participants to provide some benefits and limitations of the researchteaching nexus questionnaire and the concept mapping technique. The academics' answers were analysed and offered some insights to improve the proposed activities.

\section{Results and discussion}

The collaborative concept map produced during the group session can be seen in Figure 5 . The participants started the discussion by asking themselves "where" exactly the tensions between teaching and research occur. Using their individual maps (Figure 4), they realised

Figure 5.

A collaborative concept map of the group's perspective of the research-teaching nexus

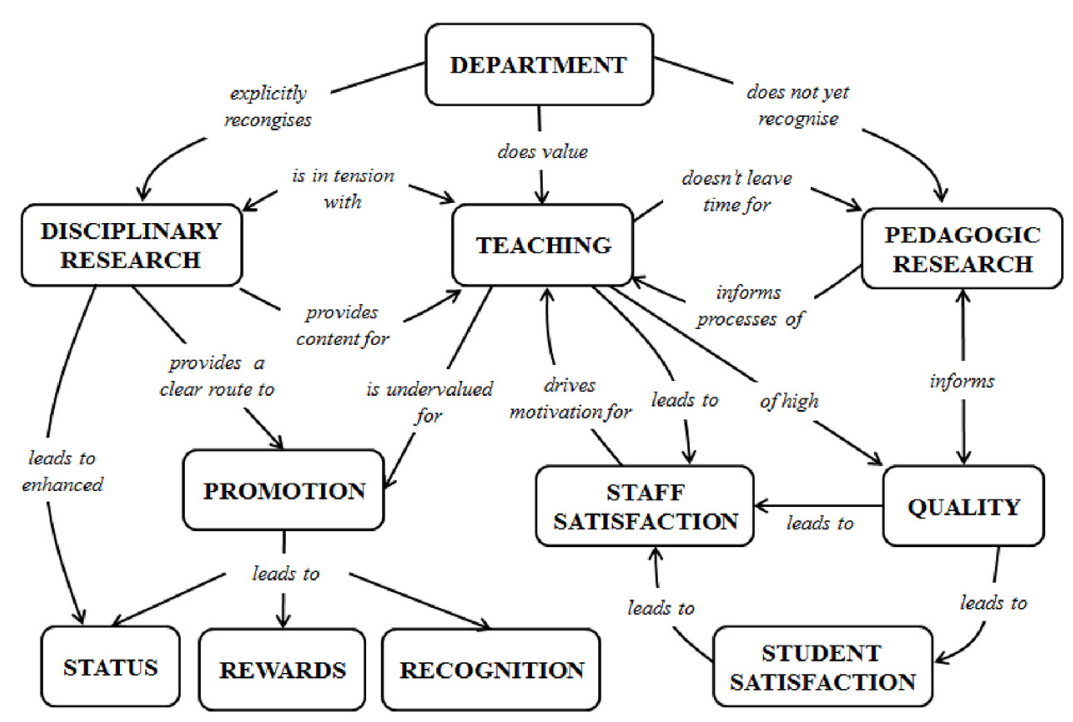


that "academia" and "university" are wider social institutions with heterogeneous values, which might not reflect the particularities of the Department of Biochemical Sciences. For them, the discussion needs to be undertaken at the departmental level, leading them to choose the concept of "department" to start the concept map.

Another point of discussion occurred with the concept of "research" in the individual maps (Figure 4). They split this concept into two types of research: disciplinary, subjectspecific research (Biochemistry) and pedagogic research (Scholarship of Teaching and Learning). Tension arises because the Department of Biochemical Sciences explicitly recognises the subject-specific research but does not yet recognise pedagogic research. Teaching is the concept that connects both types of research and they chose to put it between disciplinary and pedagogic research (Figure 5).

The concepts at the bottom of the map were negotiated considering the asymmetric status, rewards, recognition and motivation that come from teaching and research activities (see an example in Figure 4). The participants all agreed that there is a huge perceived asymmetry for these activities. Whilst disciplinary research provides a "clear route[4]" for promotion and, consequently, high status, rewards and recognition, pedagogic research leads to staff and student satisfaction, though this is poorly defined in terms of recognition and promotion within the department. As we can see in Figure 5 , there is no direct connection between both sides of the map, providing a good insight into research and teaching nexus. It is important to note that the collaborative map summarises the main ideas discussed during the group session. The participants' individual knowledge structures (highlighted by the questionnaire and the individual concept map) were modified over the collaborative process leading to a product that is not the sum of their knowledge but a transformed and new structure (Lee et al., 2015).

Figure 6 shows a graph that summarises the participants' evaluation of the questionnaire and the individual concept maps.

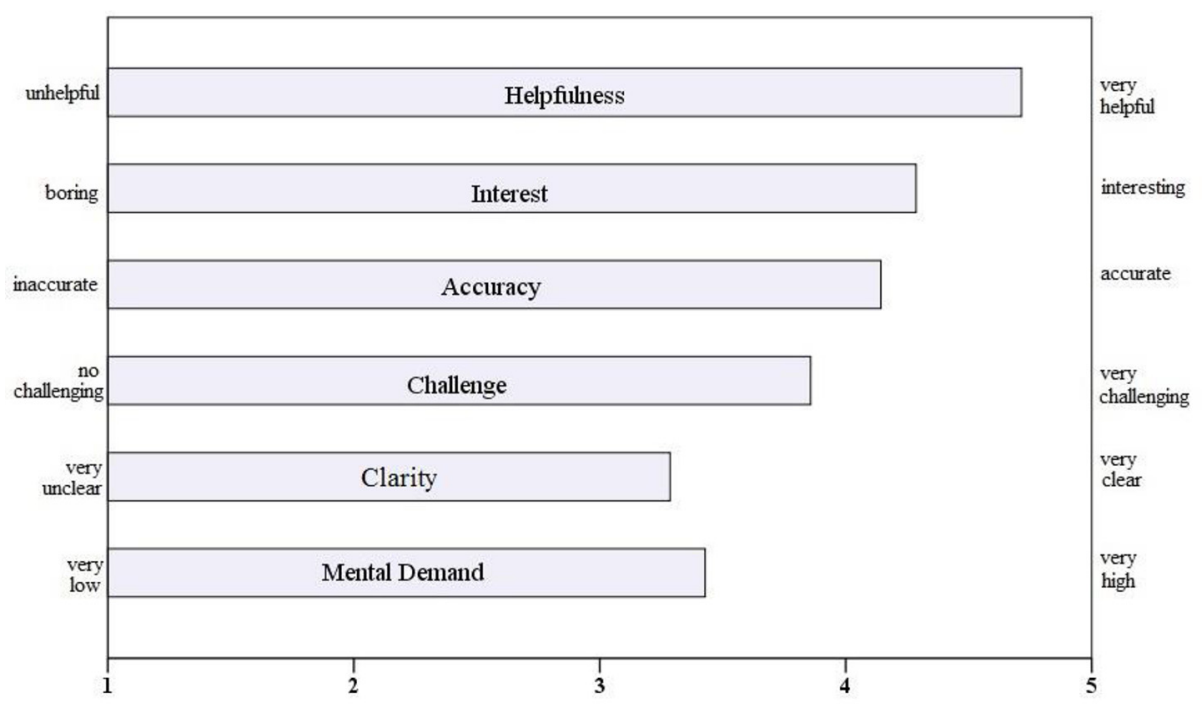

Note: The average score is illustrated in each evaluation scale

Figure 6. Participants' feedback about the questionnaire and the concept map 
PRR

3,2

As we can see in Figure 6, answering the questionnaire did not require a very high mental activity from the participants (mean $=3.4$ ), indicating that the cognitive load imposed by this activity does not lead to an overload situation (Sweller et al., 2011). However, some improvements need to be made to the questions to increase their level of clarity (mean $=3.2$ ). Some participants pointed out the lack of clarity as a questionnaire limitation, for example:

- Research could be clearer in the questionnaire as a pedagogic- vs disciplinespecific.

- Some of the questions were a little ambiguous, so could be interpreted in different ways. However, this gives space for participant interpretation.

- It was hard to understand through the survey what the question poser in some questions, which meant that we essentially answered different questions, which probably changed our maps slightly.

The participants also declared that the questionnaire offered a challenge $($ mean $=3.9)$ to them without being boring (mean $=4.3$ ). The feedback regarding the level of helpfulness (mean $=4.7$ ) and accuracy $($ mean $=4.2$ ) was important in the re-design the questionnaire. For them, not only was the individual concept map an accurate representation of their point of view, but it was also very helpful to visualise their perspective about the relationship between research and teaching within the Department of Biochemical Sciences:

- Consciously consider of how these things fit together and perhaps plan how to try to move the balance in the future.

- See other team members' perspectives on it, these are people you work with daily, and sometimes it can explain their approach to certain scenarios.

- It was a good process to go through to highlight common areas with other team members and how sometimes we approach things in different ways.

- Overall, the concept maps seemed accurate and were hugely helpful for producing a team map.

- Interesting exercise. It clarifies the focal points, personally and for the team.

\section{Final considerations}

Engagement with the questionnaire has the benefit of:

- Providing the participants with an example of an excellent concept map produced from the questionnaire results. Very often, subject-expert/novice mappers tend to concentrate on adding material (making the map bigger) rather than reflecting on the content and refining the quality of the links. The process defined in this manuscript, therefore, helps in the construction of succinct maps with a high degree of explanatory power.

- Sensitising the participants to the concepts involved and the possible links between them. Rather than going into the group discussion "cold", the construction of a map through the questionnaire helps to make explicit the areas that are appropriate for discussion (i.e. boundaries for the map) concepts that might populate the structure. 
- Facilitating the sharing of perspectives within a group by allowing peers to see how the ideas are linked in each other's minds. This offers a more detailed window into their thinking than would be provided, for example, by a list of key ideas.

- Introducing novice participants to the potential benefits of consensus maps in teambased projects that could be translated into the direct teaching environment.

\section{Notes}

1. The research-teaching nexus is concerned with how research and teaching are connected in academics' lives. It refers to the perceptions on whether research is seen as a product or as a process and the relative importance of these activities to their professional identities.

2. To have access to the survey please use the password 'unlock' and the following link: https://goo. $\mathrm{gl} / \mathrm{wK} 4 \mathrm{qCa}$ (18 October).

3. The evaluation form can be accessed using the link: https://goo.gl/wYDjrb (18 October).

4. For them, a 'clear route' towards promotion means that they are aware of the department expectations regarding disciplinary research - it is clear what they need to do in order to gain promotion (e.g. publish papers in mainstream journals and get research grants).

\section{References}

Aguiar, J.G. and Correia, P.R.M. (2017), "From representing to modelling knowledge: proposing a twostep training for excellence in concept mapping", Knowledge Management \& E-Learning, Vol. 9 No. 3, pp. 366-379.

Amadieu, F., van Gog, T., Paas, F., Tricot, A. and Mariné, C. (2009), "Effects of prior knowledge and concept-map structure on disorientation, cognitive load, and learning", Learning and Instruction, Vol. 19 No. 5, pp. 376-386.

Blunt, J.R. and Karpicke, J.D. (2014), "Learning with retrieval-based concept mapping”, Journal of Educational Psychology, Vol. 106 No. 3, pp. 849-858.

Brown, J.S., Collins, A. and Duguid, P. (1989), "Situated cognition and the culture of learning", Educational Researcher, Vol. 18 No. 1, pp. 32-42.

Cañas, A.J. and Novak, J.D. (Eds) (2006), "Re-examining the foundations for effective use of concept maps", Proceedings of the Sec. Intl. Conference on Concept Mapping, Universidad de Costa Rica, San Jose, Costa Rica, pp. 247-255.

Cañas, A.J., Novak, J.D. and Reiska, P. (2015), "How good is my concept map? Am I a good cmapper?", Knowledge Management and E-Learning, Vol. 7 No. 1, pp. 6-19.

Conradty, C. and Bogner, F.X. (2010), "Implementation of concept mapping to novices: reasons for errors, a matter of technique or content?", Educational Studies, Vol. 36 No. 1, pp. 47-58.

Correia, P.R.M. and Aguiar, J.G. (2014), "Concept mapping informed by Cognitive Load Theory: implications for tasks involving learner-generated Cmaps", in Correia, P.R.M., InfanteMalachias, M.E., Cañas, A.J. and Novak, J.D. (Eds), Concept Mapping for Learning and Innovation, Proceedings of the Sixth International Conference on Concept Mapping, Santos, Brazil, 2014, USP and IHMC, Brazil, pp. 150-157.

Correia, P.R.M., Cicuto, C.A.T. and Aguiar, J.G. (2014), "Using novakian concept maps to foster peer collaboration in higher education", in Ifenthaler, D. and Hanewald, R. (Orgs.). Digital Knowledge Maps in Education, Springer, New York, NY, pp. 195-217.

Creswell, J.W. (2013), Research Design: qualitative, Quantitative and Mixed Methods Approaches, London, Sage. 
PRR

3,2

De Lisi, R. and Goldbeck, S.L. (1999), "Implication of piagetian theory for peer learning", in O’Donnell, A.M. and King, A. (Eds), Cognitive Perspectives on Peer Learning, Lawrence Erlbaum Associates, Mahwah, NJ, pp. 3-37.

Derbentseva, N. and Kwantes, P. (2014), "Cmap readability: propositional parsimony, map layout and semantic clarity and flow", in Correia, P.R.M., Infante-Malachias, M.E., Cañas, A.J. and Novak, J. D. (Eds), Concept Mapping for Learning and Innovation in Proc. of the Sixth Intl. Conference on Concept Mapping, Santos, SP, pp. 86-93.

Deutsch, M. (2003), "Cooperation and conflict. A personal perspective on the history of the social psychological study of conflict resolution", in West, M.A., Tjosvold, D. and Smith, K.G. (Eds), International Handbook of Organizational Teamwork and Cooperative Working, Wiley, Chichester, pp. 9-43.

Dillenbourg, P., Baker, M., Blaye, A. and O'Malley, C. (1995), "The evolution of research on collaborative learning", in Reimann, P. and Spada, H. (Eds), Learning in Humans and Machines: Towards an Interdisciplinary Learning Science, Elsevier, Oxford, pp. 189-211.

Fischer, F. and Mandl, H. (2003), "Being there or being where? Videoconferencing and cooperative learning", in van Oostendorp, H. (Ed.), Cognition in a Digital World, Lawrence Erlbaum Associates, Mahwah, NJ, pp. 205-223.

Fischer, F., Bruhn, J., Gräsel, C. and Mandl, H. (2002), "Fostering collaborative knowledge construction with visualisation tools", Learning and Instruction, Vol. 12 No. 2, pp. 213-232.

Hatano, G. and Inagaki, K. (1991), "Sharing cognition through collective comprehension activity", in L. Resnick, J.M. Levine and S.D. Teasley, (Eds), Perspectives on Socially Shared Cognition, American Psychological Association, Washington, DC, pp. 331-348.

Hay, D., Kinchin, I.M. and Lygo-Baker, S. (2008), "Making learning visible: the role of concept mapping in higher education", Studies in Higher Education, Vol. 33 No. 3, pp. 295-311.

Hilbert, T.S. and Renkl, A. (2008), "Concept mapping as a follow-up strategy to learning from texts: what characterizes good and poor mappers?", Instructional Science, Vol. 36 No. 1, pp. 53-73.

Hoffman, R.R. and Lintern, G. (2006), "Eliciting and representing the knowledge of experts", in Ericsson, K.A., Charness, N., Feltovich, P. and Hoffman, R. (Eds), Cambridge Handbook of Expertise and Expert Performance, Cambridge University Press, New York, NY, pp. 203-222.

Kinchin, I.M. (2014), "Concept mapping as a learning tool in higher education: a critical analysis of recent reviews", The Journal of Continuing Higher Education, Vol. 62 No. 1, pp. 39-49.

Kinchin, I.M. (2016), Visualising Powerful Knowledge to Develop the Expert Student: A Knowledge Structures Perspective on Teaching and Learning at University, Sense Publishers, Rotterdam.

Kinchin, I.M. (2017), "Visualising the pedagogic frailty model as a frame for the scholarship of teaching and learning", PSU Research Review, Vol. 1 No. 3, pp. 184-193.

Kinchin, I.M. and Winstone, N.E. (Eds) (2017), Pedagogic Frailty and Resilience in the University, Sense Publishers, Rotterdam.

Kinchin, I.M., Alpay, E., Curtis, K., Franklin, J., Rivers, C. and Winstone, N.E. (2016), "Charting the elements of pedagogic frailty", Educational Research, Vol. 58 No. 1, pp. 1-23.

Kinchin, I.M., Hosein, A., Medland, E., Lygo-Baker, S., Warburton, S., Gash, D., Rees, R., Loughlin, C., Woods, R., Price, S. and Usherwood, S. (2017), "Mapping the development of a new MA programme in higher education: comparing private perceptions of a public endeavour", Journal of Further and Higher Education, Vol. 41 No. 2, pp. 155-171.

Kobbe, L., Weinberger, A., Dillenbourg, P., Harrer, A., Hämäläinen, R., Häkkinen, P. and Fischer, F. (2007), "Specifying computer-supported collaboration scripts", International Journal of Computer-Supported Collaborative Learning, Vol. 2 Nos 2/3, pp. 211-224.

Lee, D., Huh, Y. and Reigeluth, C.M. (2015), "Collaboration, intragroup conflict, and social skills in project-based learning”, Instructional Science, Vol. 43 No. 5, pp. 561-590. 
Lygo-Baker, S., Kingston, E. and Hay, D.B. (2008), "Uncovering the diversity of teachers' understanding of their role: the importance of individual values", The International Journal of Learning, Vol. 15 No. 5, pp. 245-253.

McMillan, W. and Gordon, N. (2017), "Being and becoming a university teacher", Higher Education Research and Development, Vol. 36 No. 4, pp. 777-790.

McNaughton, S., Barrow, M., Bagg, W. and Frielick, S. (2016), "Capturing the integration of practicebased learning with beliefs, values and attitudes using modified concept mapping", Journal of Medical Education and Curricular Development, Vol. 3, pp. 17-24.

Mayer, R.E. and Moreno, R. (2009), "Nine ways to reduce cognitive load in multimedia learning", Educational Psychologist, Vol. 38 No. 1, pp. 43-52.

Novak, J.D. (2010), Learning, Creating, and Using Knowledge: Concept Maps as Facilitative Tools in Schools and Corporations, Routledge, London.

O'Donnell, A.N. and Dansereau, D.F. (1992), "Scripted cooperation in student dyads: a method for analyzing and enhancing academic learning and performance", in Hertz-Lazarowitz, R. and Miller, N. (Eds), Interactions in Cooperative Groups. The Theoretical Anatomy of Group Learning, Cambridge University Press, Cambridge, MA, pp. 120-141.

Ritchhart, R., Turner, T. and Hadar, L. (2009), "Uncovering students' thinking about thinking using concept maps", Metacognition and Learning, Vol. 4 No. 2, pp. 145-159.

Roth, W.-M. and Roychoudhury, A. (1993), "The concept map as a tool for the collaborative construction of knowledge: a microanalysis of high school physics students", Journal of Research in Science Teaching, Vol. 30 No. 5, pp. 503-534.

Rowland, S.L. and Myatt, P.M. (2014), "Getting started in the scholarship of teaching and learning: a 'how to' guide for science academics", Biochemistry and Molecular Biology Education, Vol. 42 No. 1, pp. 6-14.

Shavelson, R.J., Ruiz-Primo, M.A. and Wiley, E.W. (2005), “Windows into the mind”, Higher Education, Vol. 49 No. 4, pp. 413-430.

Stull, A.T. and Mayer, R.E. (2007), "Learning by doing versus learning by viewing: three experimental comparisons of learner-generated versus author-provided graphic organizers", Journal of Educational Psychology, Vol. 99 No. 4, pp. 808-820.

Sweller, J., Ayres, P. and Kalyuga, S. (2011), Cognitive Load Theory, Springer, New York, NY.

Teasley, S. (1997), "Talking about reasoning: how important is the peer in peer collaboration?", in Resnick, L.B., Säljö, R., Pontecorvo, C. and Burge, B. (Eds), Discourse, Tools and Reasoning: Essays on Situated Cognition, Springer, Berlin, pp. 361-384.

Torres, P.L. and Marriott, R.C.V. (2010), Handbook of Research on Collaborative Learning Using Concept Mapping, IGI Global, Hershey.

van Boxtel, C., van der Linden, J. and Kanselaar, G. (1997), “Collaborative construction of conceptual understanding: interaction processes and learning outcomes emerging from a concept mapping and a poster task", Journal of Interactive Learning Research, Vol. 8 Nos 3/4, pp. 341-361.

van den Bogaart, A.C., Schaap, H., Hummel, H.G. and Kirschner, P.A. (2017), “Combining concept maps and interviews to produce representations of personal professional theories in higher vocational education: effects of order and vocational domain”, Instructional Science, Vol. 45 No. 3, pp. 359-376.

van Merriënboer, J.J.G. and Ayres, P. (2005), "Research on cognitive load theory and its design implications for e-learning", Educational Technology Research and Development, Vol. 53 No. 3, pp. 5-13.

van Mierlo, C.M., Jarodzka, H., Kirschner, F. and Kirschner, P.A. (2012), “Cognitive load theory in e-learning”, in Yan, Z. (Ed.), Encyclopedia of Cyber Behavior, Information Science Reference, EUA, pp. 1178-1211.

Weinberger, A., Stegmann, K. and Fischer, F. (2007), "Knowledge convergence in collaborative learning: concepts and assessment”, Learning and Instruction, Vol. 17 No. 4, pp. 416-426. 
PRR

3,2

100

\section{About the authors}

Joana G. Aguiar is a Researcher in science education at the University of São Paulo, Brazil. Joana G. Aguiar is the corresponding author and can be contacted at: joanaguilares@usp.br

Alfred E. Thumser is a Senior Teaching Fellow in Biochemistry in the Department of Biochemical Sciences at the University of Surrey, UK.

Sarah G. Bailey is a Teaching Fellow in Physiology in the Department of Biochemical Sciences at the University of Surrey, UK.

Sarah L. Trinder is a Teaching Fellow in Pharmacology in the Department of Biochemical Sciences at the University of Surrey, UK.

Ian Bailey is a Teaching Fellow in Toxicology in the Department of Biochemical Sciences at the University of Surrey, UK.

Danielle L. Evans is a PhD student in the Department of Biochemical Sciences at the University of Surrey, UK.

Ian M. Kinchin is a Professor of Higher Education within the Department of Higher Education at the University of Surrey, UK.

For instructions on how to order reprints of this article, please visit our website: 